\title{
Cyclic Peptides Synthesis with the Assistance of a Removable Activating Group
}<smiles>CC(C)(C)c1cc([C@H](C(=O)OCc2ccccc2)N(C(=O)OCc2ccccc2)C(C)(C)C)ccc1O</smiles>

(3.0 equiv)

(a) oxidative cross-coupling

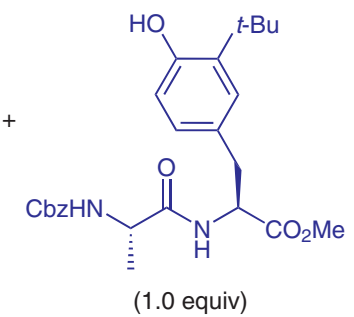

(1.0 equiv)
Fe[TPP]Cl (1 mol\%) $m$-CРBA (2.0 equiv) $\mathrm{CH}_{2} \mathrm{Cl}_{2}$, r.t.

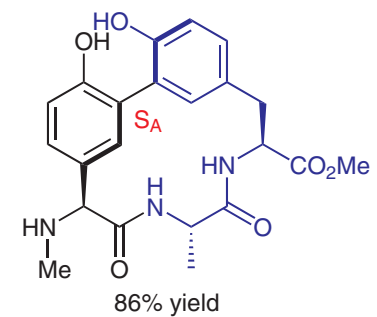

\begin{tabular}{l|l} 
(c) & HOTf $(6.0$ equiv) \\
HFIP, r.t., $16 \mathrm{~h}$
\end{tabular}<smiles>CC(=O)OC(=O)N[C@@H](C)C(=O)N[C@@H](C)Cc1cc(-c2cc(C(C(=O)OCc3ccccc3)N(C)C(=O)OCc3ccccc3)cc(C(C)(C)C)c2O)c(O)c(C(C)(C)C)c1</smiles>

$$
\begin{aligned}
& \text { 1. } \mathrm{Pd} / \mathrm{C}(10 \mathrm{~mol} \%) \\
& \mathrm{H}_{2}(1 \mathrm{~atm}) \\
& \text { EtOH, r.t., } 2 \mathrm{~h} \\
& \text { 2. PyBOP (2.0 equiv) } \\
& \text { DMAP (3.0 equiv) } \\
& \text { MeCN, r.t., } 16 \mathrm{~h} \\
& \text { (b) } \\
& \text { macrolactamization }
\end{aligned}
$$<smiles>CC(=O)OC(C)Cc1cc(-c2cc(C(C(=O)N[C@@H](C)C(=O)N[C@H](C)C(=O)OC(C)(C)C)N(C)C(C)(C)C)cc(C(C)(C)C)c2O)c(O)c(C(C)(C)C)c1</smiles>

$48 \%$ yield

Other examples:<smiles>CC(C)(C)OC(=O)N[C@@H](Cc1ccc(O)c(C(C)(C)C)c1)C(=O)N1CCC[C@H]1C(=O)OCc1ccccc1</smiles><smiles>CC(=O)N[C@H](Cc1ccc(O)c(C(C)(C)C)c1)C(=O)OCc1ccccc1</smiles>

\section{$(a-c)$ \\ $56 \%$ yield \\ (3 steps)}<smiles>CC[C@@H](Cc1ccc(O)c(-c2cc(C[C@H](N)C(=O)N3CCC[C@H]3C(=O)N[C@@H](C)C(=O)O)ccc2O)c1)C(C)=O</smiles><smiles>CC(C)(C)c1cc(C[C@H](NC(=O)OCc2ccccc2)C(=O)NC(C(=O)OCc2ccccc2)C(=O)OCc2ccccc2)ccc1O</smiles><smiles>CC(=O)N[C@@H](Cc1ccc(O)cc1)C(=O)N[C@@H](Cc1ccc(O)c(C(C)(C)C)c1)C(C)=O</smiles>

$\underset{\begin{array}{c}46 \% \text { yield } \\ \text { (3 steps) }\end{array}}{\stackrel{(a-c)}{\longrightarrow}}$<smiles>CCC(C)[C@H](NC(=O)[C@H](N)Cc1ccc(O)c(-c2cc(C[C@H](NC(=O)[C@H](Cc3ccc(O)cc3)NC(C)=O)C(C)=O)ccc2O)c1)C(C)=O</smiles>

\section{Key words}

oxidative crosscoupling

cyclic peptides

biaryl-bridged peptides

activating group
Significance: Biaryl-bridged cyclic peptides are becoming more and more important due to their biological activity. The authors have developed an efficient strategy to synthesize these peptides by introducing a removable activating group to increase reactivity in the oxidative cross-coupling step that forms the biaryl unit.
Comment: Although the authors have prepared some natural and nonnatural biaryl-bridged cyclic peptides in moderate total yields, this approach with a remarkable activating group ( $t$-Bu) might have more synthetic uses. 